\title{
Les Modernités de Victor Hugo, textes édités par David Ellison et Ralph Heyndels
}

Judith Wulf

\section{(2) OpenEdition}

1 Journals

\section{Édition électronique}

URL : http://journals.openedition.org/studifrancesi/9285

DOI : 10.4000/studifrancesi.9285

ISSN : 2421-5856

Éditeur

Rosenberg \& Sellier

\section{Édition imprimée}

Date de publication : 1 juin 2008

Pagination : 208-209

ISSN : 0039-2944

\section{Référence électronique}

Judith Wulf, «Les Modernités de Victor Hugo, textes édités par David Ellison et Ralph Heyndels », Studi Francesi [En ligne], 154 (LII | I) | 2008, mis en ligne le 30 novembre 2015, consulté le 13 janvier 2021. URL : http://journals.openedition.org/studifrancesi/9285; DOI : https://doi.org/10.4000/studifrancesi. 9285

Ce document a été généré automatiquement le 13 janvier 2021.

\section{(c) (†) $\ominus$}

Studi Francesi è distribuita con Licenza Creative Commons Attribuzione - Non commerciale - Non opere derivate 4.0 Internazionale. 


\title{
Les Modernités de Victor Hugo, textes édités par David Ellison et Ralph Heyndels
}

\author{
Judith Wulf
}

\section{RÉFÉRENCE}

Les Modernités de Victor Hugo, textes édités par David eluison et Ralph HEYNDELs, Fasano, Schena Editore / Presses de l'Université Paris-Sorbonne, 2004, pp. 182.

1 Cet ouvrage reprend les textes des contributions présentées lors du colloque Les Modernités de Victor Hugo, organisé par D. ELLISON, R. HEYNDELS et R. PIRSON au Musée d'Art Lowe de l'Université de Miami les 15 et 16 novembre 2002. Il s'agit d'un sujet qui, de Baudelaire à nos jours, en passant par le fameux Avez-vous lu Victor Hugo? d'Aragon, constitue une problématique critique récurrente. Deux manières d'évaluer la modernité de Hugo se côtoient dans ce livre: une partie des communications posent le problème du legs hugolien et, partant, de son actualité; d'autres prennent pour étalon de mesure les premiers écrivains reconnus par la modernité, Baudelaire et Rimbaud. La contribution de Victor BROMBERT (pp. 11-26), qu'on peut classer dans le premier type de démarche, analyse «la voix prophétique» de Hugo comme la marque d'un «sens triomphant de renouvellement et de vitalité». Loin du Hugo attaché à des valeurs désormais dépassées, Brombert cherche à mettre en perspective les tensions dynamiques qui conservent à son écriture toute «sa puissance poétique et prophétique». Partant du célèbre mot de Breton «Hugo est surréaliste quand il n'est pas bête», William PAULSON (pp. 27-39) choisit de mettre en avant la première partie - plus positive - de ce jugement, en l'étudiant dans Les Travailleurs de la mer. C'est également le roman choisi par Roselyne PIRSON (pp. 41-53). S'intéressant au manuscrit illustré, elle cherche à montrer que sa modernité ne réside pas seulement dans les techniques picturales utilisées pour le dessin, mais également dans la réflexion théorique sur le 
livre d'artiste dont il jette les bases, témoignant de la recherche d'un langage nouveau «à la croisée du signe textuel et du signe visuel». C'est aux fins de roman que s'intéresse pour sa part Kathryn M. GROSSMAN (pp. 55-67) dans son étude «Hugolian endings, Back to the future in the novels and their adaptation». Utilisant les adaptations comme révélatrices des particularités de l'écriture, elle souligne notamment le caractère ambigu des fins de roman et la représentation du dispositif historique complexe comme marque d'une écriture singulière qui excite encore l'intérêt aujourd'hui. Pour Délia MATA-CIAMPOLI (pp. 69-78), c'est dans les créations dramatiques musicales qu'il faut chercher la vitalité de l'œuvre hugolienne qui, de l'opéra à la comédie musicale, a inspiré les metteurs en scène à travers les époques et les continents. Béatrice DIDIER (pp. 79-106), quant à elle, s'intéresse à la complexité biographique du Victor Hugo raconté par Adèle Hugo et souligne son apport théorique pour un type de recherche emblématique du poststructuralisme. Avec une étude portant le titre suggestif de «L'ombre de Hugo» David ELLISON (pp. 107-123) inaugure la série des études consacrées aux rapports entre Hugo et Baudelaire. Comparant les deux poètes et interrogeant leurs rapports réciproques, il se demande «comment décrire et comprendre l'ombre jetée par Hugo sur Baudelaire» et, à rebours, «comment Baudelaire a [...] réinventé la poésie en se dégageant de cette ombre». Poursuivant l'examen de la «mise à mort de Hugo dont le poète des Fleurs $d u$ mal serait l'auteur», Pierre BRUNEL (pp. 125-138) étudie la duplicité des liens qui unissent et opposent les deux poètes. Dans une perspective un peu différente, Giovanni DотоLI (pp. 139-164) propose une lecture chronologique de leur relation, qu'il retrace pas à pas. En clôture de ce volume, Ralph HEYNDELS (pp. 165-180) s'intéresse aux relations entre Hugo et un autre poète dont la modernité est rarement mise en cause, Rimbaud. Au-delà du contenu et de la forme d'une poésie qui ne nous touche plus de la même manière que ses contemporains, subsistent les «visions», la capacité de «voyance» d'un Hugo dont la modernité serait «en creux». 